\title{
Catalytic activity of supported solid catalysts for phenol hydroxylation
}

\author{
B. P. Nethravathi $\cdot$ K. Ramakrishna Reddy • \\ K. N. Mahendra
}

Published online: 19 February 2014

(c) Springer Science+Business Media New York 2014

\begin{abstract}
Cobalt(II), copper(II) and zinc(II) complexes of 2-phenylbenzimidazole $(\mathrm{PhBzlH})$ encapsulated in the supercages of zeolite-Y and ZSM-5 have been synthesized and characterized by spectroscopic studies (IR, UV/visible, EPR), elemental analyses, thermal studies and X-ray diffraction patterns. The catalytic activity of encapsulated complexes was investigated for the hydroxylation of phenol using $30 \% \mathrm{H}_{2} \mathrm{O}_{2}$ as an oxidant. Under optimized reaction conditions, the hydroxylation of phenol yielded catechol and hydroquinone as the major products. All catalysts show good selectivity for diphenol products. A maximum conversion of phenol was obtained with $[\mathrm{Cu}(\mathrm{PhBzlH})]-\mathrm{Y}$ as the catalyst. The results showed that conversion of phenol varies in the order $[\mathrm{Cu}(\mathrm{PhBzlH})]-\mathrm{Y}$ $(53 \%)>[\mathrm{Cu}(\mathrm{PhBzlH})]-\mathrm{ZSM}-5>(49 \%)>[\mathrm{Co}(\mathrm{PhBzlH})]-$ ZSM-5 $(47 \%)>[\mathrm{Co}(\mathrm{PhBzlH})]-\mathrm{Y}(46 \%)>[\mathrm{Zn}(\mathrm{PhBzlH})]-$ $\mathrm{Y}(45 \%)>[\mathrm{Zn}(\mathrm{PhBzlH})]-\mathrm{ZSM}-5(41 \%)$ after $6 \mathrm{~h}$ of reaction time. Test for the recyclability of the reaction was also carried out and the results indicate their recyclability.
\end{abstract}

Keywords Zeolite - Encapsulation - Hydrogen peroxide . Catalyst · Phenol

B. P. Nethravathi

Department of Chemistry, Vijaya College, R.V. Road,

Bangalore 560 004, India

K. Ramakrishna Reddy

Department of Chemistry, Government Science College,

Bangalore 560 001, India

K. N. Mahendra $(\bowtie)$

Department of Chemistry, Bangalore University,

Bangalore 560 001, India

e-mail: knmahendra@gmail.com

\section{Introduction}

Immobilization of homogeneous catalysts to a solid support has received wide attention as these materials have advantages of both homogeneous and heterogeneous catalysis. The supported catalysts enhance their thermal stability, selectivity, recyclability and easy separation from reaction products. The non corrosive, environment friendly and economically viable nature of the zeolite catalysed reactions also lead them to use in various industrial processes such as catalytic cracking, hydrocracking, isomerization and oxidation [1]. Zeolite encapsulated metal complexes are one of such materials for heterogeneization of homogeneous catalysts. These zeolite encapsulated metal complexes were used in various organic reactions like carbonylation, hydroformylation, hydrogenation, oxidation, hydroxylation etc. [2-8].

Use of solid catalysts for selective oxidation of phenols preferably at near-ambient conditions and using clean oxidants like $\mathrm{O}_{2}$ or $\mathrm{H}_{2} \mathrm{O}_{2}$ is a research area of growing importance. Hydroxylation of phenol with $\mathrm{H}_{2} \mathrm{O}_{2}$ using microporous titanosilicate, TS- 1 and its commercial utilization by Erichem workers [9] is a major advance in this area. Hydroquinone and catechol are obtained with high selectivity over TS-1. Strong mineral acids or Fenton's reagent are other efficient catalysts for the hydroxylation of phenol using $\mathrm{H}_{2} \mathrm{O}_{2}$ as the oxidant, producing peroxonium ion and hydroxyl radical, respectively. Various metal phthalocyanines have been studied for the hydroxylation of phenol by $\mathrm{H}_{2} \mathrm{O}_{2}$ [10]. It was found that the metal ion of the catalyst influences both activity and selectivity of the reaction as well as the distribution of catechol and hydroquinone. Since $\mathrm{H}_{2} \mathrm{O}_{2}$ alone is not a hydroxylating agent, catalysts have to be added to make it a hydroxylating agent. An active oxidant for the hydroxylation of phenol is an 


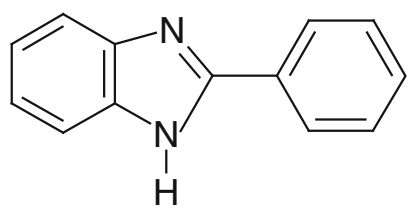

Scheme 1 2-phenylbenzimidazole (PhBzlH)

ionic species formed by the activation or reaction of $\mathrm{H}_{2} \mathrm{O}_{2}$ with metal phthalocyanines. Bimetallic $\mathrm{Sn}-\mathrm{Mo}$ and $\mathrm{Sn}-\mathrm{Sb}$ phthalocyanines have also been used to hydroxylate phenols using $\mathrm{H}_{2} \mathrm{O}_{2}$ as the oxidant [11].

Already we reported the heterogeneous catalytic system by preparing $\mathrm{Co}(\mathrm{II}), \mathrm{Cu}(\mathrm{II})$ and $\mathrm{Zn}$ (II) complexes of 2-methyl and 2,2-aminophenylbenzimidazole in the supercages of zeolite $\mathrm{Y}$ and ZSM-5 and catalytic activity for the oxidation of phenol studied $[12,13]$. Synthesis and characterization of 2-phenylbenzimidazole complexes were reported earlier [14], but they have not reported as zeolite encapsulated complexes.

In this work, studies on the synthesis and characterization of zeolite $\mathrm{Y}$ and ZSM-5 encapsulated complexes of $\mathrm{Co}(\mathrm{II}), \mathrm{Cu}(\mathrm{II})$ and $\mathrm{Zn}(\mathrm{II})$ with 2-phenylbenzimidazole ligand $(\mathrm{PhBzlH})$ are presented. The structure of the 2-phenylbenzimidazole ligand $(\mathrm{PhBzlH})$ was shown in Scheme 1. Applications of these complexes for hydroxylation of phenol was studied and the results of these studies are discussed.

\section{Experimental section}

\subsection{Materials}

Protonated form of zeolite $\mathrm{Y}$ [H-Y] [Si to $\mathrm{Al}$ ratio 5.07] and ZSM-5 [H-ZSM-5] [Si to Al ratio 21.31] were purchased from Sud-Chemie, Mumbai. L R-Grade solvents used were purified according to the literature method [15]. The chemicals used for the studies were of AR grade and purchased from Merck. 2-phenylbenzimidazole was prepared according to the literature method [16].

\subsection{Physicochemical characterization}

The metal content was estimated using Perkin-Elmer model ICP-AES instrument. The surface areas of the zeolite samples were determined by the BET method of nitrogen adsorption at liquid nitrogen temperature by BET method on a NOVA-1000 Ver. 3.70 instrument. Powder X-ray diffraction patterns of zeolite HY, H-ZSM-5 and the zeolite encapsulated complexes were recorded using Philips X'Pert diffractometer using $\mathrm{CuK}_{\alpha}(\lambda=0.15405 \mathrm{~nm})$ target with nickel filter. Thermogravimetric analysis was recorded on a NETZSCH STA 409 PG/PC under nitrogen atmosphere for the encapsulated complex with the heating rate of $10{ }^{\circ} \mathrm{C} / \mathrm{min}$ from 30 to $800{ }^{\circ} \mathrm{C}$. The morphology of the sample was examined using Philips scanning electron microscopy. Infrared spectra of the ligand, simple complex and supported complexes in the region $4,000-400 \mathrm{~cm}^{-1}$ were recorded as $\mathrm{KBr}$ pellet on a FTIR-8400S Shimadzu, spectrophotometer. The diffuse reflectance spectra were recorded at room temperature in the range $200-800 \mathrm{~nm}$ using $\mathrm{BaSO}_{4}$ as reference on a Shimadzu UV-Visible-NIR model UV-3101P instrument. The X-band EPR spectra of powdered samples of zeolite encapsulated $\mathrm{Cu}$ (II) complexes were recorded at room temperature on a VARIAN E-112 ESR spectrometer and the $g$ values were estimated relative to tetracyanoethylene (TCNE, $g=2.0027$ ). Shimadzu 14B gas chromatograph fitted with FID detector connected with BP-5 capillary column was used to analyze the reaction products of the catalytic activity studies.

\subsection{Preparation of complexes}

Protonated form of zeolite Y (H-Y) or H-ZSM-5 (5 g) sample was stirred in an aqueous solution of the respective metal salt taken in a $100 \mathrm{ml}$ round bottom flask. The mixture was refluxed with stirring for $12 \mathrm{~h}$ on an oil bath. It was filtered and washed with water till the washings were free from metal ions and then dried in an oven at $150{ }^{\circ} \mathrm{C}$ for $24 \mathrm{~h}$. This metal exchanged zeolite was treated with 2-phenylbenzimidazole in acetone medium and then refluxed with stirring for $24 \mathrm{~h}$ on an oil bath. The reaction mixture was filtered, washed with DMF and then with acetone using Soxhlet apparatus to remove any unreacted ligand and the metal complex adsorbed on the zeolite surface. The resulting solution was treated with aqueous $0.01 \mathrm{M} \mathrm{NaCl}$ with stirring for $15 \mathrm{~h}$ to allow exchange of uncomplexed metal ions with sodium ions. The zeolite encapsulated complex was then filtered, washed with distilled water to remove any chloride ions present and dried at $150{ }^{\circ} \mathrm{C}$ for $24 \mathrm{~h}$.

\subsection{Catalytic activity measurements}

\subsubsection{Decomposition of $\mathrm{H}_{2} \mathrm{O}_{2}$}

An aqueous solution of $30 \% \mathrm{H}_{2} \mathrm{O}_{2}(4 \mathrm{ml}, 5.54 \mathrm{~g})$ was added to $2 \mathrm{mmol}$ catalyst and it was stirred for 1 and $2 \mathrm{~h}$ at room temperature. The catalyst was then separated out by filtration and washed with distilled water. The filtrate containing partially decomposed $\mathrm{H}_{2} \mathrm{O}_{2}$ and the washings were collected in a $250 \mathrm{ml}$ volumetric flask, and then made up to the mark with distilled water. Then $10 \mathrm{ml}$ of this solution was titrated against standard $\mathrm{KMnO}_{4}$ solution to estimate the unreacted $\mathrm{H}_{2} \mathrm{O}_{2}$ [17]. 
Table 1 Percentage of metal, colour and the surface area measurement data

\begin{tabular}{|c|c|c|c|c|c|}
\hline $\begin{array}{l}\text { Sl. } \\
\text { no. }\end{array}$ & Compound & Colour & $\begin{array}{l}\text { Metal } \\
(\mathrm{wt} \%)\end{array}$ & $\begin{array}{l}\mathrm{S}_{\mathrm{BET}} \\
\left(\mathrm{m}^{2} / \mathrm{g}\right)^{\mathrm{a}}\end{array}$ & $\begin{array}{l}\text { Pore } \\
\text { volume } \\
(\mathrm{cc} / \mathrm{g})^{\mathrm{b}}\end{array}$ \\
\hline 1 & $\mathrm{H}-\mathrm{Z}-\mathrm{Y}^{\mathrm{c}}$ & White & - & 25.8 & 0.105 \\
\hline 2 & H-ZSM-5 ${ }^{\mathrm{d}}$ & White & - & 258.7 & 0.179 \\
\hline 3 & {$[\mathrm{Co}(\mathrm{PhBzlH})]-\mathrm{Y}$} & Pink & 0.935 & 20.41 & 0.095 \\
\hline 4 & {$[\mathrm{Co}(\mathrm{PhBzlH})]-\mathrm{ZSM}$} & White & 0.037 & 122.3 & 0.100 \\
\hline 5 & {$[\mathrm{Cu}(\mathrm{PhBzlH})]-\mathrm{Y}$} & $\begin{array}{l}\text { Dirty } \\
\text { white }\end{array}$ & 3.135 & 15.13 & 0.035 \\
\hline 6 & {$[\mathrm{Cu}(\mathrm{PhBzlH})]-\mathrm{ZSM}-5$} & $\begin{array}{l}\text { Dirty } \\
\text { white }\end{array}$ & 0.089 & 78.23 & 0.098 \\
\hline 7 & {$[\mathrm{Zn}(\mathrm{PhBzlH})]-\mathrm{Y}$} & White & 2.314 & 23.80 & 0.052 \\
\hline 8 & {$[\mathrm{Zn}(\mathrm{PhBzlH})]-\mathrm{ZSM}-5$} & White & 0.245 & 192.98 & 0.152 \\
\hline
\end{tabular}

${ }^{a} \mathrm{~S}_{\mathrm{BET}}=$ specific surface area measured by BET method

b Pore volume calculated from $\mathrm{N}_{2}$ desorption by the BJH method

${ }^{c} \mathrm{H}-\mathrm{Z}-\mathrm{Y}$ and ${ }^{\mathrm{d}} \mathrm{H}-\mathrm{ZSM}-5$ = protonated form of zeolite-Y and ZSM-5

\subsubsection{Hydroxylation of phenol}

The reactions were carried out in a $50 \mathrm{ml}$ double-necked round bottom flask fitted with a water cooled condenser. In a typical reaction, phenol $(2.35 \mathrm{~g}, 0.025 \mathrm{~mol})$ and $30 \%$ aqueous $\mathrm{H}_{2} \mathrm{O}_{2}(4 \mathrm{ml}, 0.05 \mathrm{~mol}, 5.54 \mathrm{~g})$ were dissolved in $2 \mathrm{ml}$ of acetonitrile and the reaction mixture was heated on an oil bath at $80{ }^{\circ} \mathrm{C}$ with continuous stirring. Then $2.5 \mathrm{mmol}$ of the catalyst was added and the reaction was considered to begin. Aliquots were drawn from the reaction mixture at regular intervals for analysis using a gas chromatograph.

\section{Results and discussion}

\subsection{Synthesis and characterization of catalysts}

Synthesis of the metal complexes encapsulated in the zeolite cages of H-Y and H-ZSM-5 was carried out by the flexible ligand method [18]. The metal content in the encapsulated complex was determined by using the ICP instrument. The analysis of metal content along with the colour of the complexes and the surface area measurements are given in Table 1 .

To compare the properties of neat with encapsulated complexes, the neat complexes of $\mathrm{Co}(\mathrm{II}), \mathrm{Cu}$ (II) and $\mathrm{Zn}$ (II) with $\mathrm{PhBzlH}$ were also prepared and characterized by various physicochemical techniques. The analytical data proposed is in good agreement with the data available in literature [14].

The significant reduction in surface area and pore volume as a result of encapsulation of complexes within the

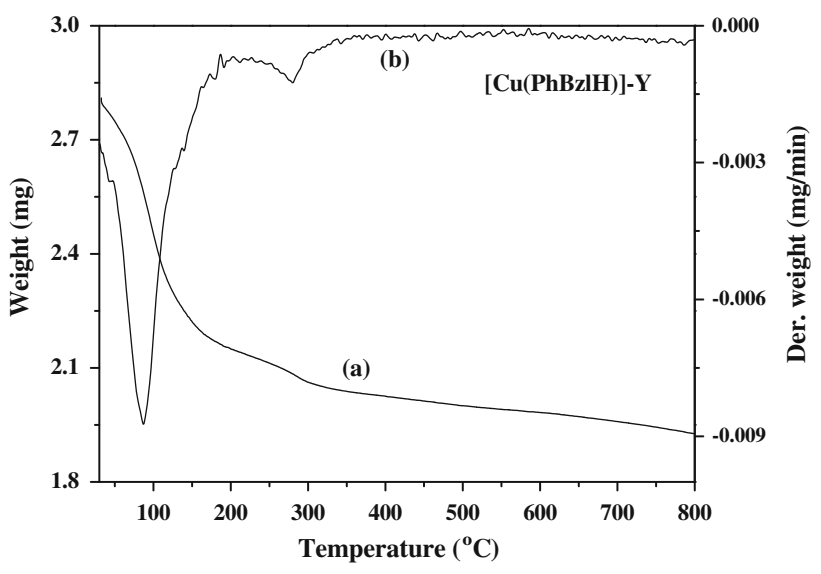

Fig. $1 \boldsymbol{a}$ TGA and $\boldsymbol{b}$ DTG curves of $[\mathrm{Cu}(\mathrm{PhBzlH})]-\mathrm{Y}$

Table 2 Thermogravimetric analysis data of encapsulated $\mathrm{PhBzlH}$ complexes

\begin{tabular}{|c|c|c|c|c|}
\hline $\begin{array}{l}\text { Sl. } \\
\text { no. }\end{array}$ & Complex & $\begin{array}{l}\text { Temperature } \\
\text { range }\left({ }^{\circ} \mathrm{C}\right)\end{array}$ & $\begin{array}{l}\text { Weight } \\
\text { loss }(\%)\end{array}$ & Group lost \\
\hline \multirow[t]{3}{*}{1} & \multirow[t]{3}{*}[\mathrm{Co}(\mathrm{PhBzlH})]{$-\mathrm{Y}$} & $56-170$ & 15.52 & $\mathrm{nH}_{2} \mathrm{O}$ \\
\hline & & $170-340$ & 5.48 & $\mathrm{H}_{2} \mathrm{O}+\mathrm{Cl}^{-}$ \\
\hline & & $340-690$ & 1.61 & $\mathrm{~L}$ \\
\hline \multirow[t]{3}{*}{2} & \multirow[t]{3}{*}[\mathrm{Co}(\mathrm{PhBzlH})]{$-\mathrm{ZSM}-5$} & $52-185$ & 3.8 & $\mathrm{nH}_{2} \mathrm{O}$ \\
\hline & & $185-628$ & 4.1 & $\mathrm{H}_{2} \mathrm{O}+\mathrm{Cl}^{-}$ \\
\hline & & $628-725$ & 0.29 & $\mathrm{~L}$ \\
\hline \multirow[t]{3}{*}{3} & \multirow[t]{3}{*}[\mathrm{Cu}(\mathrm{PhBzlH})]{$-\mathrm{Y}$} & $32-184$ & 22.86 & $\mathrm{nH}_{2} \mathrm{O}$ \\
\hline & & $184-315$ & 3.93 & $\mathrm{H}_{2} \mathrm{O}$ \\
\hline & & $315-800$ & 4.28 & $\mathrm{~L}$ \\
\hline \multirow[t]{3}{*}{4} & \multirow[t]{3}{*}[\mathrm{Cu}(\mathrm{PhBzlH})]{$-\mathrm{ZSM}-5$} & $38-206$ & 7.39 & $\mathrm{nH}_{2} \mathrm{O}$ \\
\hline & & $206-607$ & 5.65 & $\mathrm{H}_{2} \mathrm{O}$ \\
\hline & & $607-800$ & 2.39 & $\mathrm{~L}$ \\
\hline \multirow[t]{3}{*}{5} & \multirow[t]{3}{*}[\mathrm{Zn}(\mathrm{PhBzlH})]{$-\mathrm{Y}$} & $43-216$ & 18.58 & $\mathrm{nH}_{2} \mathrm{O}$ \\
\hline & & $216-655$ & 6.80 & $\mathrm{H}_{2} \mathrm{O}$ \\
\hline & & $655-800$ & 1.20 & $\mathrm{~L}$ \\
\hline \multirow[t]{3}{*}{6} & \multirow[t]{3}{*}[\mathrm{Zn}(\mathrm{PhBzlH})]{$-\mathrm{ZSM}-5$} & $36-148$ & 6.0 & $\mathrm{nH}_{2} \mathrm{O}$ \\
\hline & & $148-645$ & 7.11 & $\mathrm{H}_{2} \mathrm{O}$ \\
\hline & & $645-800$ & 1.12 & $\mathrm{~L}$ \\
\hline
\end{tabular}

$L$ Ligand

zeolite pores is due to the blocking of the pores by the formation of the metal complexes [19]. The decrease in surface area values suggests the formation of metal complexes inside the zeolite cages.

\subsection{Thermogravimetric analysis}

Thermal stability of the encapsulated complex was studied using TGA and DTG. Representative TGA and DTG curves 
of the $[\mathrm{Cu}(\mathrm{PhBzlH})]-\mathrm{Y}$ complex are shown in Fig. 1. The thermogravimetric analysis data for all the complexes are presented in Table 2. The weight loss of the encapsulated complexes can be clearly observed in DTG and it occurs in two or three steps in the temperature range of $32-800{ }^{\circ} \mathrm{C}$. All the encapsulated complexes show almost similar decomposition pattern. The first stage of mass loss up to around $200{ }^{\circ} \mathrm{C}$ corresponds to the removal of lattice water molecule present in zeolite cavities [5]. In the second stage, expel of coordinated water molecules (if any) and anions can be expected. So, the encapsulated complexes decompose only at a higher temperature than that for the simple complexes. Due to the encapsulation, complexes become more thermally stable. A very small weight loss was observed and it may be due to the presence of low metal complex in the zeolite cavities [1]. This is in agreement with the low metal content as estimated by the ICP instrument.

\subsection{Powder X-ray diffraction studies}

The powder X-ray diffraction patterns of H-Y, H-ZSM-5 and the encapsulated complexes were recorded at $2 \theta$ values of $5-80^{\circ}$. Essentially very similar patterns are formed for the encapsulated complexes as compared to the starting zeolite $\mathrm{H}-\mathrm{Y}$ and H-ZSM-5, though slight changes in the intensity of the bands are seen. These observations indicate that the crystalline nature of the zeolite is retained even after the encapsulation of the complex. No new peaks were detected in the XRD patterns of the encapsulated complex possibly due to the presence of low content of the metal complexes.

\subsection{Infrared spectral studies}

The selected spectral data is presented in the Table 3. The infrared spectral data of the ligand and complexes reveal the co-ordination of the ligand to the metal ion. The infrared spectra of the ligand exhibit a band at around $3,050 \mathrm{~cm}^{-1}$,

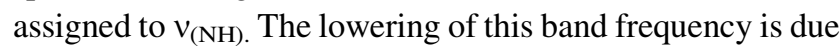
to association through the intermolecular hydrogen bonding [20]. The $v_{(\mathrm{C}=\mathrm{N})}$ and $v_{(\mathrm{C}=\mathrm{C})}$ vibrations are very close and occur around $1,620 \mathrm{~cm}^{-1}$. The band around $1,590 \mathrm{~cm}^{-1}$ is assigned to the $\mathrm{NH}$ in-plane bending. Another band appearing at $1,541 \mathrm{~cm}^{-1}$ may be due to $\delta_{\mathrm{C}-\mathrm{H}}$ vibration. The $\mathrm{v}_{\mathrm{C}-\mathrm{N}}$ and $\delta_{\mathrm{N}-\mathrm{H}}$ appear around $1,313 \mathrm{~cm}^{-1}$. The Substituted phenyl group shows ring vibrations at 1,485 and $740 \mathrm{~cm}^{-1}$. The bands around $1,409,1,276,1,002,615$ and $430 \mathrm{~cm}^{-1}$ are assigned to the benzimidazole ring vibrations. The weak band around $780 \mathrm{~cm}^{-1}$ is ascribed to NH out-of-plane bending vibration.

The infrared spectra of the complexes are similar to those of the corresponding ligands. An upward shift $\left(5-15 \mathrm{~cm}^{-1}\right)$ of the $v_{(\mathrm{C}=\mathrm{N})}$ in the IR spectra of the complexes as compared to their values in the free ligand, suggests coordination through the pyridine nitrogen of imidazoline. The other bands in the spectrum of each complex are similar to those in the corresponding ligand spectrum except for slight shifts in their positions and changes in their intensities due to coordination. These empirical band assignments have been made on the basis of earlier reported assignments by other workers earlier [14, 21].

All metal complexes encapsulated in zeolites exhibit bands around 1,100, 950, 800 and $750 \mathrm{~cm}^{-1}$ which arise from zeolite framework. We have not observed any broadening and shift in the positions of the zeolite vibrational bands, which indicates that no change has occurred in the zeolite framework. This clearly indicates that, the metal complexes fit well within the cavities of the zeolites.

\subsection{Electronic spectral studies}

The electronic spectral data of ligand, neat and encapsulated complexes recorded using $\mathrm{BaSO}_{4}$ as references are given in Table 4.

Table 3 Partial IR spectral data of PhBzlH and its complexes

\begin{tabular}{lllllll}
\hline Compound & $\begin{array}{l}v_{\mathrm{N}-\mathrm{H}} \\
\left(\mathrm{cm}^{-1}\right)\end{array}$ & $\begin{array}{l}v_{\mathrm{C}=\mathrm{N}} / \mathrm{v}_{\mathrm{C}=\mathrm{C}} \\
\left(\mathrm{cm}^{-1}\right)\end{array}$ & $\begin{array}{l}\mathrm{N}-\mathrm{H} \text { in-plane } \\
\text { bending }\left(\mathrm{cm}^{-1}\right)\end{array}$ & $\begin{array}{l}\delta_{\mathrm{C}-\mathrm{H}} \\
\left(\mathrm{cm}^{-}\right)\end{array}$ & $\begin{array}{l}v_{\mathrm{C}-\mathrm{N}} / \delta_{\mathrm{N}-\mathrm{H}} \\
\left(\mathrm{cm}^{-1}\right)\end{array}$ & $\begin{array}{l}\mathrm{N}-\mathrm{H} \text { out-of-plane- } \\
\text { bending }\left(\mathrm{cm}^{-1}\right)\end{array}$ \\
\hline $\mathrm{PhBzlH}$ & 3,045 & 1,617 & 1,587 & 154 & 1,308 & 787 \\
{$[\mathrm{Co}(\mathrm{PhBzlH})]$} & 3,055 & 1,629 & 1,573 & 1,540 & 1,309 & 781 \\
{$[\mathrm{Co}(\mathrm{PhBzlH})]-\mathrm{Y}$} & $\mathrm{a}$ & 1,629 & 1,577 & 1,541 & $\mathrm{a}$ & $\mathrm{a}$ \\
{$[\mathrm{Co}(\mathrm{PhBzlH})]-Z S M$} & $\mathrm{a}$ & 1,635 & 1,560 & 1,307 & 1,309 & 774 \\
{$[\mathrm{Cu}(\mathrm{PhBzlH})]$} & 3,056 & 1,629 & 1,566 & 1,540 & 1,311 & $\mathrm{a}$ \\
{$[\mathrm{Cu}(\mathrm{PhBzlH})]-\mathrm{Y}$} & $\mathrm{a}$ & 1,624 & 1,570 & 1,544 & 1,330 & $\mathrm{a}$ \\
{$[\mathrm{Cu}(\mathrm{PhBzlH})]-Z S M$} & $\mathrm{a}$ & 1,628 & 1,570 & 1,542 & 1,310 & 781 \\
{$[\mathrm{Zn}(\mathrm{PhBzlH})]$} & 3,055 & 1,620 & 1,587 & 1,544 & 1,313 & $\mathrm{a}$ \\
{$[\mathrm{Zn}(\mathrm{PhBzlH})]-Y$} & $\mathrm{a}$ & 1,630 & 1,578 & 1,550 & 1,311 & $\mathrm{a}$ \\
{$[\mathrm{Zn}(\mathrm{PhBzlH})]-Z S M$} & $\mathrm{a}$ & 1,637 & 1,579 &
\end{tabular}

$\mathrm{a}=$ bands not resolved due to overlap with zeolite bands 
Table 4 Electronic spectral data of $\mathrm{PhBzlH}$ and its complexes

\begin{tabular}{llll}
\hline S1. no. & Compound & $\lambda_{\max }(\mathrm{nm})$ & Tentative assignments \\
\hline 1 & {$[\mathrm{Co}(\mathrm{PhBzlH})]$} & 658 & $\mathrm{~d}-\mathrm{d}$ \\
2 & {$[\mathrm{Co}(\mathrm{PhBzlH})]-\mathrm{Y}$} & 520 & $\mathrm{~d}-\mathrm{d}$ \\
3 & {$[\mathrm{Co}(\mathrm{PhBzlH})]-\mathrm{ZSM}$} & 374 & Charge transfer \\
& & 581 & $\mathrm{~d}-\mathrm{d}$ \\
4 & {$[\mathrm{Cu}(\mathrm{PhBzlH})]$} & 397 & Charge transfer \\
& & 614 & $\mathrm{~d}-\mathrm{d}$ \\
5 & {$[\mathrm{Cu}(\mathrm{PhBzlH})]-\mathrm{Y}$} & 413 & Charge transfer \\
& & 765 & $\mathrm{~d}-\mathrm{d}$ \\
6 & {$[\mathrm{Cu}(\mathrm{PhBzlH})]-\mathrm{ZSM}$} & 377 & Charge transfer \\
& & 765 & $\mathrm{~d}-\mathrm{d}$ \\
7 & {$[\mathrm{Zn}(\mathrm{PhBzlH})]$} & 380 & Charge transfer \\
8 & {$[\mathrm{Zn}(\mathrm{PhBzlH})]-\mathrm{Y}$} & - & - \\
9 & {$[\mathrm{Zn}(\mathrm{PhBzlH})]-\mathrm{ZSM}$} & 395 & Charge transfer \\
\hline
\end{tabular}

The electronic spectrum of the PhBzlH exhibits three peaks at 213, 250 and $300 \mathrm{~nm}$ due to $\pi-\pi^{*}$ transitions of benzimidazole moiety. Due to the low intensity of the observed bands some uncertainties arise in the detailed assignments of the bands for the complexes. The bands at higher frequencies can be due to charge transfer transitions, which is evident from the high intensity of these bands.

The electronic spectrum of cobalt (II) neat complex is characterized by the highest energy ${ }^{4} \mathrm{~A}_{2} \rightarrow{ }^{4} \mathrm{~T}_{1(\mathrm{P})}$ transition at $658 \mathrm{~nm}$ is typical of tetrahedral $\mathrm{Co}(\mathrm{II})$ complexes [22]. Similar observations were made in the case of encapsulated complexes which suggest that the cobalt complex with tetrahedral geometry were formed inside the zeolite cavities. A broad band observed around $614 \mathrm{~nm}$ in neat $\mathrm{Cu}(\mathrm{II})$ complex is assigned to the ${ }^{2} \mathrm{~B}_{1 \mathrm{~g}} \rightarrow{ }^{2} \mathrm{~A}_{1 \mathrm{~g}}$ transition. In case of encapsulated complexes the bands are observed at $765 \mathrm{~nm}$ with an additional charge transfer transition band. The transition observed supports a square planar geometry for the copper complex formed inside the zeolite cavities [23].

The white coloured neat and encapsulated complexes of $\mathrm{Zn}$ (II) shows three bands at around $217-300 \mathrm{~nm}$ due to the $\pi-\pi^{*}$ transitions of benzimidazole moiety. As expected no bands due to $\mathrm{d}-\mathrm{d}$ transitions are observed in case of neat and encapsulated $\mathrm{Zn}$ (II) complexes [23] and the Zn(II) neat complex has a tetrahedral configuration which is realized by participation of the pyridine nitrogen of two organic ligand molecules, and two nitrate anions, typical for these classes of organic ligands [14].

\subsection{EPR spectra}

The EPR spectra of $\mathrm{Cu}(\mathrm{II})$ encapsulated complexes were recorded at room temperature using TCNE as reference. The spectra obtained are as shown in Figs. 2 and 3.

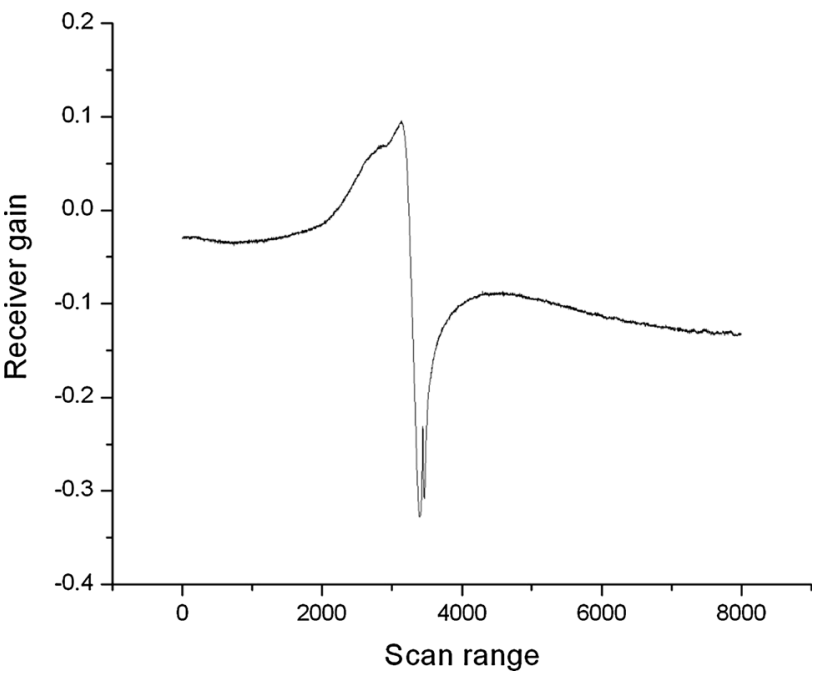

Fig. 2 EPR spectrum of $[\mathrm{Cu}(\mathrm{PhBzlH})]$ complexes

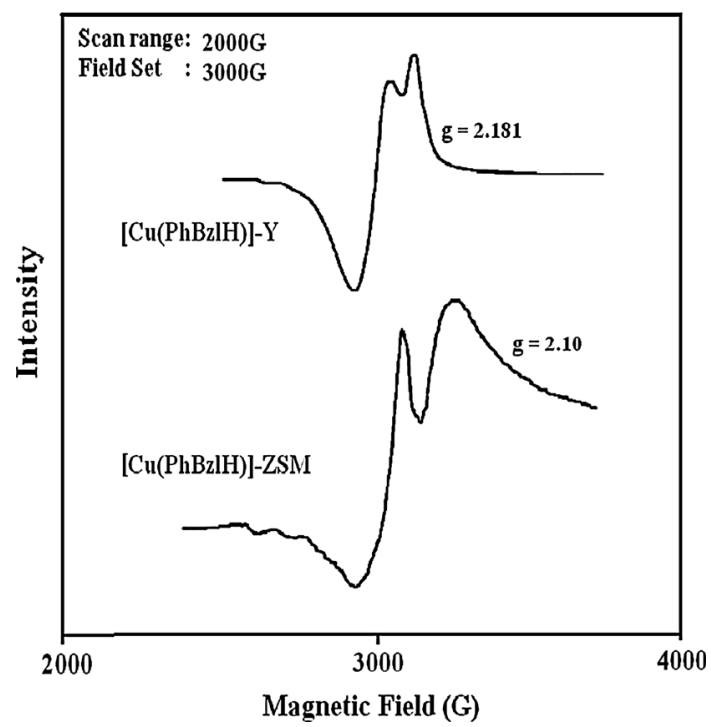

Fig. 3 EPR spectrum of $\mathrm{Cu}$ encapsulated $\mathrm{PhBzlH}$ complexes

Neat complexes showed broad EPR spectra corresponding to nearest neighbor spin-spin interactions and the $\mathrm{g}$ average is found to be 2.19. Whereas in the zeoliteencapsulated metal complexes the $\mathrm{g}$ average values are found to be 2.18 and 2.10 for ZY and ZSM-5 complexes. The spectra of encapsulated complexes are almost similar to that of the neat complexes. The $g$ values of the zeoliteencapsulated complexes are similar to that of the neat complexes [24].

For copper complexes the $\mathrm{g}$ values are found to be 2.18 and 2.10 and are $<2.3$ indicating that these complexes possess considerable covalent character in the metal ligand bond. The interactions of the zeolite framework with the 
encapsulated complex could induce some distortions in the expected structure.

\subsection{Catalytic activity studies}

\subsubsection{Decomposition of $\mathrm{H}_{2} \mathrm{O}_{2}$}

The catalytic activity for the decomposition of $\mathrm{H}_{2} \mathrm{O}_{2}$ with the encapsulated complexes was studied. The quantity of $\mathrm{H}_{2} \mathrm{O}_{2}$ that reacted and the turn over frequency (TOF) at two different time intervals ( 1 and $2 \mathrm{~h}$ ) were measured. The results are tabulated in Table 5, which shows that the decomposition of $\mathrm{H}_{2} \mathrm{O}_{2}$ is slow initially but increases with time. This is due to the fact that the encapsulated complex used requires relatively longer time to exhibit maximum catalytic activity as the number of metal centers is less compared with that of the neat complex [25]. Hence increasing the duration of the reaction is a very effective way of carrying out the reaction with $\mathrm{H}_{2} \mathrm{O}_{2}$ as the source of oxygen.

\subsubsection{Hydroxylation of phenol}

The catalytic hydroxylation of phenol using different encapsulated complexes was studied as a function of time using $\mathrm{H}_{2} \mathrm{O}_{2}$ as the oxidant and acetonitrile as the solvent. Catechol and hydroquinone were obtained as the major products, as shown in Scheme 2. No minor products were detected in GC under the conditions employed here.

The reaction was carried out for $6 \mathrm{~h}$ of reaction time with the optimized condition (2.35 g phenol, $4 \mathrm{ml} \mathrm{H}_{2} \mathrm{O}_{2}$, $2.5 \mathrm{mmol}$ catalyst in $2 \mathrm{ml}$ of acetonitrile at $80{ }^{\circ} \mathrm{C}$ ) for all the catalysts. The effect of different catalysts on the conversion of phenol and percentage selectivity of catechol and hydroquinone is represented in Fig. 4.

Table 5 Percentage decomposition of $\mathrm{H}_{2} \mathrm{O}_{2}$

\begin{tabular}{|c|c|c|c|c|}
\hline \multirow{2}{*}{ Catalyst $^{\mathrm{a}}$} & \multicolumn{2}{|l|}{ After $1 \mathrm{~h}$} & \multicolumn{2}{|l|}{ After $2 \mathrm{~h}$} \\
\hline & $\begin{array}{l}\mathrm{H}_{2} \mathrm{O}_{2} \\
\text { reacted (\%) }\end{array}$ & $\begin{array}{l}\text { TOF } \\
\left(\mathrm{h}^{-1}\right)^{\mathrm{b}}\end{array}$ & $\begin{array}{l}\mathrm{H}_{2} \mathrm{O}_{2} \\
\text { reacted (\%) }\end{array}$ & $\begin{array}{l}\text { TOF } \\
\left(\mathrm{h}^{-1}\right)^{\mathrm{b}}\end{array}$ \\
\hline$[\mathrm{Co}(\mathrm{PhBzlH}))]-\mathrm{Y}$ & 0.160 & 66.72 & 1.45 & 300.38 \\
\hline $\begin{array}{l}[\mathrm{Co}(\mathrm{PhBzlH}))]- \\
\text { ZSM }\end{array}$ & 14.160 & 36.00 & 18.03 & 22.91 \\
\hline$[\mathrm{Cu}(\mathrm{PhBzlH}))]-\mathrm{Y}$ & 1.836 & 241.39 & 4.173 & 274.31 \\
\hline $\begin{array}{l}[\mathrm{Cu}(\mathrm{PhBzlH}))]- \\
\mathrm{ZSM}\end{array}$ & 14.39 & 47.53 & 77.78 & 44.66 \\
\hline$[\mathrm{Zn}(\mathrm{PhBzlH}))]-\mathrm{Y}$ & 2.34 & 429.41 & 2.587 & 475.42 \\
\hline $\begin{array}{l}[\mathrm{Zn}(\mathrm{PhBzlH}))]- \\
\mathrm{ZSM}\end{array}$ & 14.416 & 6.225 & 17.025 & 3.676 \\
\hline
\end{tabular}

$\overline{\mathrm{TOF}}=$ moles of the substrate converted per mole of the (metal) in the solid catalyst per hour
The maximum conversion of phenol obtained is with $[\mathrm{Cu}(\mathrm{PhBzlH})]-\mathrm{Y}$. The order of catalytic activity for hydroxylation of phenol is found to be as follow. $[\mathrm{Cu}(\mathrm{PhBzlH})]-\mathrm{Y}(53 \%)>[\mathrm{Cu}(\mathrm{PhBzlH})]-\mathrm{ZSM}-5>(49 \%)$ $>[\mathrm{Co}(\mathrm{PhBzlH})]-\mathrm{ZSM}-5(47 \%)>[\mathrm{Co}(\mathrm{PhBzlH})]-\mathrm{Y}(46 \%)$ $>[\mathrm{Zn}(\mathrm{PhBzlH})]-\mathrm{Y} \quad(45 \%)>[\mathrm{Zn}(\mathrm{PhBzlH})]-\mathrm{ZSM}-5 \quad(41 \%)$ after $6 \mathrm{~h}$ of reaction time. The different performance of the individual catalysts may be attributed to the $\mathrm{d}$ configuration of the metal ion/atom in the complex and geometry of the respective metal complexes [26].

A maximum conversion of $40 \%$ to catechol and $14 \%$ to hydroquinone formation was obtained with $[\mathrm{Cu}(\mathrm{PhBzlH})]-\mathrm{Y}$ as catalyst. The order of catechol formation with different catalysts is as follows: $[\mathrm{Cu}(\mathrm{PhBzlH})]-\mathrm{Y}>[\mathrm{Zn}(\mathrm{PhBzlH})]-$ $\mathrm{Y}>[\mathrm{Cu}(\mathrm{PhBzlH})]-\mathrm{ZSM}>[\mathrm{Co}(\mathrm{PhBzlH})]-\mathrm{Y}>[\mathrm{Co}$ $(\mathrm{PhBzlH})]-\mathrm{ZSM}>[\mathrm{Zn}(\mathrm{PhBzlH})]-\mathrm{ZSM}$.

The hydroquinone formation for different catalysts employed follows the order as below: [ $\mathrm{Zn}(\mathrm{PhBzlH})]-$ $\mathrm{ZSM}>[\mathrm{Co}(\mathrm{PhBzlH})]-\quad \mathrm{ZSM}>[\mathrm{Cu}(\mathrm{PhBzlH})]-\quad \mathrm{ZSM}>$ $[\mathrm{Co}(\mathrm{PhBzlH})]-\mathrm{Y}>[\mathrm{Cu}(\mathrm{PhBzlH})]-\mathrm{Y}>[\mathrm{Zn}(\mathrm{PhBzlH})]-\mathrm{Y}$. In all the catalysts, the selectivity is much more for catechol than hydroquinone.<smiles>CCOS(=O)(=O)[C@](O)(O[Na])c1cccc(O)c1O</smiles>

Scheme 2 Hydroxylation of phenol

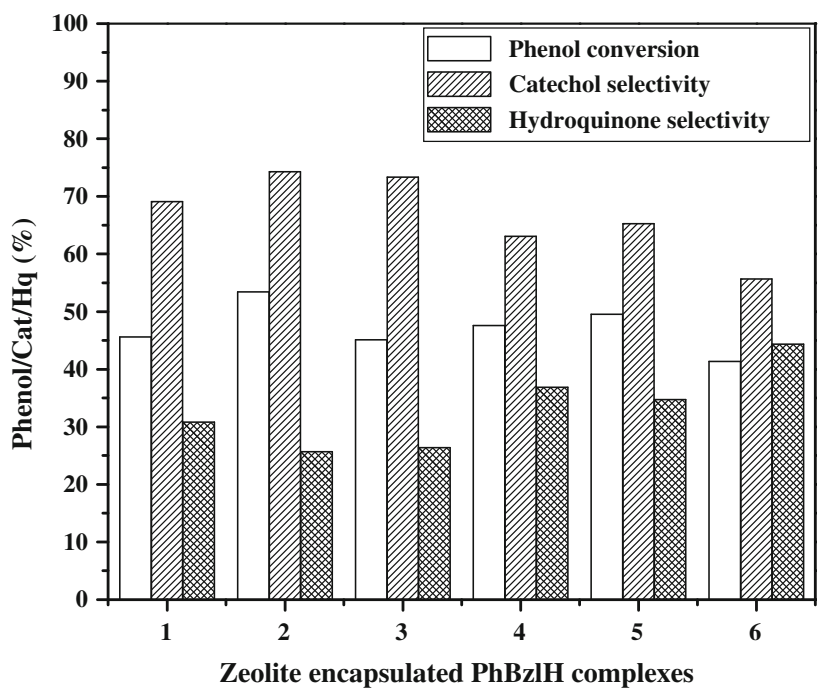

Fig. 4 Comparison of phenol conversion and catechol and hydroquinone selectivity with zeolite encapsulated complexes of $\mathrm{PhBzlH}$ 


\subsection{Recycling test}

Used catalysts were tested for their recyclability. The catalyst was separated after the reaction and was washed with acetonitrile, dried and used again with fresh reaction mixture, under the same optimized reaction condition. The products obtained were analyzed using GC. It was found that the phenol conversion was almost the same as that of the fresh run. The above procedure was repeated three times and we did not observe any loss in the catalytic activity of the encapsulated catalyst.

Leaching or decomposition of the catalysts was tested by considering blank reaction i.e. using $30 \%$ aqueous $\mathrm{H}_{2} \mathrm{O}_{2}(0.25 \mathrm{~mol})$, catalyst $(2 \mathrm{mmol})$ in $2 \mathrm{~mL}$ of acetonitrile at $80{ }^{\circ} \mathrm{C}$ for $6 \mathrm{~h}$. Absence of metal ions in mother liquor suggests no leaching or decomposition of complexes during catalytic activity.

\section{Conclusions}

Physical and spectral studies of the encapsulated zeolite clearly indicate that the encapsulation of complex occurs in the cages of zeolite. The encapsulated complexes are active catalysts for the decomposition of $\mathrm{H}_{2} \mathrm{O}_{2}$ and for the oxidation of phenol with good selectivity to catechol than hydroquinone. The IR and UV spectra of fresh and used catalysts are nearly identical with not much loss in intensity of the peaks, which indicate that these zeolite encapsulated transition metal complexes can be reused for catalytic study.

Acknowledgments The authors gratefully acknowledge the help received from Bangalore University, Bangalore for carrying out this work and BIT, Banagalore, SAIF, Kochi, Kerala, SAIF, IIT, Bombay and Department. of physics, IISc, Bangalore for the analysis.

\section{References}

1. M.R. Maurya, S.J.J. Titinchi, S. Chand, Appl. Catal. A: Gen. 228, 177 (2002)
2. P. Gellin, C. Naccache, Y.B. Taarit, Pure Appl. Chem. 8, 1315 (1988)

3. M. Iwamoto, H. Kusano, S. Kagawa, Inorg. Chem. 22, 3366 (1983)

4. S.R. Kowalak, C. Weiss, K.J. Balkus Jr, J. Chem. Soc. Chem. Commun. 57 (1991)

5. C. Ratnasamy, A. Murugkar, S. Padhye, Ind. J. Chem. 35A, 1 (1996)

6. T. Joseph, C.S. Sajanikumari, S.S. Desh Pande, S. Gopinathan, Ind. J. Chem. 38A, 792 (1999)

7. N. Ulgappan, V. Krishnasamy, Ind. J. Chem. 35A, 787 (1996)

8. C. Bronnimann, T. Mallat, A. Baiker, J. Chem. Soc. Chem. Commun. 1377 (1995)

9. Y. Masri, M. Hronee, Stud. Surf. Sci. Catal. 66, 455 (1991)

10. S. Alexander, B. Meunier, J. Chem. Soc., Chem. Commun. 15, 1799 (1994)

11. M. Hronee, G. Kiss, J. Sitek, J. Chem. Soc., Faraday Trans. 1(79), $1091(1983)$

12. B.P. Nethravathi, K.N. Mahendra, J. Porous Mater. 17, 107 (2010)

13. B.P. Nethravathi, K. Ramakrishna Reddy, K.N. Mahendra, J. Porous Mater. 18, 389 (2011)

14. S.O. Podunavac-Kuzmanovic, L.S. Vojinovic, APTEFF 34, 119 (2003)

15. D.D. Perrin, W.L.F. Armanego, D.R. Perrin, Purification of Laboratory Chemicals (Pergamon Press, Oxford, 1966)

16. D.W. Hein, R.J. Alheim, J.J. Leavitt, J. Am. Chem. Soc. 79, 427 (1957)

17. J. Bassett, R.C. Denney, G.H. Jeffery, J. Mendham, Vogel's Textbook of Quantitative Inorganic Analysis, 4th edn. (Longman Scientific and Technical, London, 1978)

18. C. Subrahmanyam, B. Louis, B.Viswanathan, A. Renken, T.K. Varadarajan, Bull. Catal. Soc. India 3 (2004)

19. K.J. Balkus Jr, A.G. Gabrielov, J. Inclusion Phenom. Mol. Recogn. Chem. 21, 159 (1995)

20. X.K. Nakamoto, Infrared and Raman Spectra of Inorganic and Coordination Compounds (Wiley, New Yark, 1986)

21. S. Rekha, K.R. Nagasundara, Ind. J. Chem. 45A, 2421 (2006)

22. S. Konstantinovic, C. Radovanovic, Z. Capic, V. Basic, J. Serb. Chem. Soc. 68, 641 (2003)

23. K. Rama Krishna Reddy, K.N. Mahendra, Russ. J. Inorg. Chem. 53(6), 906 (2008)

24. S. Deshpande, D. Srinivas, P. Ratnasamy, J. Catal. 188, 261 (1999)

25. M.R. Maurya, S.J.J. Titinchi, S. Chand, J. Mol. Catal. Chem. 193, 165 (2003)

26. K.N. Vinod, P. Puttaswamy, K.N.N. Gowda, Ind. Eng. Chem. Res. 49, 3137 (2010) 